This item was submitted to Loughborough's Research Repository by the author.

Items in Figshare are protected by copyright, with all rights reserved, unless otherwise indicated.

\title{
Two weeks of watermelon juice supplementation improves nitric oxide bioavailability but not endurance exercise performance in humans
}

PLEASE CITE THE PUBLISHED VERSION

http://dx.doi.org/10.1016/j.niox.2016.06.008

\section{PUBLISHER}

(C) Elsevier

VERSION

AM (Accepted Manuscript)

\section{PUBLISHER STATEMENT}

This work is made available according to the conditions of the Creative Commons Attribution-NonCommercialNoDerivatives 4.0 International (CC BY-NC-ND 4.0) licence. Full details of this licence are available at: https://creativecommons.org/licenses/by-nc-nd/4.0/

\section{LICENCE}

CC BY-NC-ND 4.0

\section{REPOSITORY RECORD}

Bailey, Stephen, Jamie R. Blackwell, Ewan Williams, Anni Vanhatalo, Lee J. Wylie, Paul G. Winyard, and Andrew M. Jones. 2019. "Two Weeks of Watermelon Juice Supplementation Improves Nitric Oxide Bioavailability but Not Endurance Exercise Performance in Humans". figshare. https://hdl.handle.net/2134/23174. 
Two weeks of watermelon juice supplementation improves nitric oxide bioavailability but not endurance exercise performance in humans

Stephen J. Bailey ${ }^{1}$, Jamie R. Blackwell ${ }^{1}$, Ewan Williams ${ }^{1}$, Anni Vanhatalo ${ }^{1}$, Lee J. Wylie ${ }^{1}$, Paul G. Winyard ${ }^{2}$ and Andrew M. Jones ${ }^{1}$

${ }^{1}$ Sport and Health Sciences and ${ }^{2}$ Exeter Medical School, St. Luke's Campus, University of Exeter, Heavitree Road, Exeter, EX1 2LU, United Kingdom.

Address for Correspondence:

Stephen J Bailey PhD

Tel: 01392722882

Fax: 01392264726

E-mail: S.J.Bailey@exeter.ac.uk 


\section{Abstract}

This study tested the hypothesis that watermelon juice supplementation would improve nitric oxide bioavailability and exercise performance. Eight healthy recreationally-active adult males reported to the laboratory on two occasions for initial testing without dietary supplementation (control condition). Thereafter, participants were randomly assigned, in a cross-over experimental design, to receive 16 days of supplementation with $300 \mathrm{~mL} \cdot$ day $^{-1}$ of a watermelon juice concentrate, which provided $\sim 3.4 \mathrm{~g}$ L-citrulline $\cdot$ day $^{-1}$ and an apple juice concentrate as a placebo. Participants reported to the laboratory on days 14 and 16 of supplementation to assess the effects of the interventions on blood pressure, plasma [Lcitrulline], plasma [L-arginine], plasma [nitrite], muscle oxygenation and time-to-exhaustion during severe-intensity exercise. Compared to control and placebo, plasma [L-citrulline] (29 $\pm 4,22 \pm 6$ and $101 \pm 23 \mu \mathrm{M})$, [L-arginine] $(74 \pm 9,67 \pm 13$ and $116 \pm 9 \mu \mathrm{M})$ and [nitrite] (102 \pm 29, $106 \pm 21$ and $201 \pm 106 \mathrm{nM}$ ) were higher after watermelon juice supplementation $(P<0.01)$. However, systolic blood pressure was higher in the watermelon juice (130 \pm 11$)$ and placebo $(131 \pm 9)$ conditions compared to the control condition (124 $\pm 8 \mathrm{mmHg}$; $P<0.05)$. The skeletal muscle oxygenation index during moderate-intensity exercise was greater in the watermelon juice condition than the placebo and control conditions $(P<0.05)$, but time-to-exhaustion during the severe-intensity exercise test (control: $478 \pm 80$, placebo: $539 \pm 108$, watermelon juice: $550 \pm 143$ s) was not significantly different between conditions $(P<0.05)$. In conclusion, while watermelon juice supplementation increased baseline plasma [nitrite] and improved muscle oxygenation during moderate-intensity exercise, it increased resting blood pressure and did not improve time-to-exhaustion during severe-intensity exercise. These findings do not support the use of watermelon juice supplementation as a nutritional intervention to lower blood pressure or improve endurance exercise performance in healthy adults.

Key Words: nitric oxide; L-arginine; blood pressure; muscle oxygenation; metabolism; fatigue 


\section{Introduction}

The free radical gas, nitric oxide (NO), is a multi-functional physiological signalling molecule that plays an integral role in skeletal muscle perfusion, metabolism, contractility and fatigue resistance $[1,2]$. The most recognised pathway for nitric oxide generation is the oxidation of L-arginine catalysed by the nitric oxide synthase enzymes to yield nitric oxide and L-citrulline [3]. However, while oral L-arginine supplementation can increase circulating [L-arginine] [4,5], and therefore one of the substrates for nitric oxide synthase, whether oral Larginine supplementation increases nitric oxide biomarkers (nitrate and nitrite) and improves exercise performance is controversial [4,6-9, see 10 for review]. These conflicting findings might be linked, at least in part, to significant pre-systemic [11,12] and systemic [11,13-16] breakdown of orally ingested L-arginine.

Although traditionally recognised as a product of the nitric oxide synthase-mediated oxidation of L-arginine [3], recent evidence suggests that L-citrulline can be recycled back to L-arginine [17] and is more effective than orally ingested L-arginine at increasing systemic [18,19] and muscle [20] L-arginine. It has also been reported that L-citrulline supplementation can increase the activity of nitric oxide synthase [20] and increase nitric oxide biomarkers [19,21], and there is accumulating evidence to suggest that short term supplementation with L-citrulline can improve skeletal muscle oxygenation [22], metabolism [23-24], force production [23] and fatigue resistance [22]. Therefore, short-term supplementation with L-citrulline might represent an effective dietary intervention to increase nitric oxide synthase-derived nitric oxide and to improve skeletal muscle perfusion, metabolism and exercise performance.

The name for the amino acid, L-citrulline, is derived from the Latin word for watermelon (Citrullus), from which it was first extracted [25,26, see 27 for review]. Although L-citrulline is a component of a number of different foods, watermelon juice is a particularly rich source of L-citrulline. It has been reported that watermelon juice contains $\sim 2.33 \mathrm{~g}$ of $\mathrm{L}$-citrulline per $\mathrm{L}$ of unpasteurised juice [28]. Consequently, watermelon juice ingestion has been reported to increase plasma L-citrulline [29] and L-arginine [29,30], and may also increase nitric oxide biomarkers [31]. We recently reported that seven days of supplementation with $6 \mathrm{~g} \mathrm{~L}$ citrulline day $^{-1}$ tended to, but did not significantly, increase plasma [nitrite] [22], a sensitive 
marker of nitric oxide synthase activity [32]. It has been suggested that concurrently supplementing with L-citrulline and glutathione is more effective at increasing plasma nitric oxide markers than L-citrulline alone [33]. Since watermelon is rich in glutathione [34] as well as L-citrulline, watermelon juice supplementation might represent a more effective dietary intervention to increase nitric oxide production than pure L-citrulline supplementation. Moreover, watermelon is rich in many antioxidants in addition to glutathione, including lycopene and $\beta$-carotene [34-36]. Lycopene and $\beta$-carotene may increase nitric oxide bioavailability since they have been shown to blunt the scavenging of nitric oxide by superoxide [37]. Taken together, these observations suggest that watermelon juice could be a nitric oxide precursor, but this has yet to be directly tested in humans.

Supplementation with watermelon juice has been reported to enhance aspects of vascular health in hypertensive individuals [38-41], but not in normotensive individuals [42]. It has also been reported that watermelon juice ingestion can attenuate muscle soreness after completing intense exercise [28]. The effect of watermelon juice consumption on exercise performance, on the other hand, is unclear. The acute ingestion of $500 \mathrm{~mL}$ watermelon juice, which provided a L-citrulline dose of $1.17 \mathrm{~g}$, did not improve performance during $8 \times 30 \mathrm{~s}$ cycle efforts [28], while the acute ingestion of $710 \mathrm{~mL}$ watermelon juice, which provided a $\mathrm{L}^{-}$ citrulline dose of $\sim 1 \mathrm{~g}$, did not increase the number of repetitions completed during 5 sets of bench press at $80 \%$ of the 1 repetition maximum, or increase time-to-exhaustion, the gas exchange threshold or maximal oxygen uptake during an incremental treadmill test to exhaustion [42]. Since neither of these studies [28,42] assessed plasma [L-citrulline], [Larginine] and nitric oxide biomarkers, it is unclear whether these watermelon juice interventions were effective at increasing nitric oxide production. Moreover, both these studies only administered a small acute dose of L-citrulline and it has yet to be determined whether consuming a larger L-citrulline dose through watermelon juice supplementation can improve nitric oxide biomarkers and exercise performance.

The purpose of this study was to assess the effects of chronic supplementation of watermelon juice on plasma L-citrulline, plasma L-arginine, plasma nitrite, muscle oxygenation, pulmonary oxygen uptake, and exercise performance. We hypothesised that, compared to a placebo condition, concentrated watermelon juice supplementation would increase plasma [Lcitrulline], [L-arginine] and [nitrite] and improve muscle oxygenation, pulmonary $\dot{V}_{\mathrm{O}_{2}}$ kinetics and exercise performance. 


\section{Methods}

\subsection{Subjects}

Eight healthy, recreationally-active males (mean \pm SD, age $22 \pm 2$ yr, height $1.83 \pm 0.09 \mathrm{~m}$, body mass $79 \pm 12 \mathrm{~kg}$ ) volunteered to participate in this study. None of the subjects were tobacco smokers or users of protein supplements or putative nitric oxide donors (L-citrulline, L-arginine or nitrate). The procedures employed in this study were approved by the Institutional Research Ethics Committee. All subjects gave their written informed consent prior to the commencement of the study, after the experimental procedures, associated risks, and potential benefits of participation had been explained. Subjects were instructed to arrive at the laboratory in a rested and fully hydrated state, at least $3 \mathrm{~h}$ postprandial, and to avoid strenuous exercise in the $24 \mathrm{~h}$ preceding each testing session. Each subject was also asked to refrain from caffeine and alcohol 6 and 24 h before each test, respectively. All tests were performed at the same time of day ( \pm 2 hours).

\subsection{Experimental Design}

Subjects were required to report to the laboratory on eight occasions over 7-9 weeks to complete the experimental testing (see Figure 1 for a schematic of the experimental design). On the first visit to the laboratory, subjects completed a ramp incremental exercise test for determination of the gas exchange threshold and the peak oxygen uptake ( $\left.\dot{V}_{\text {Oppeak }}\right)$. Subjects were familiarized with the two exercise performance tests employed in this study during the second laboratory testing session. After these preliminary exercise tests, subjects returned to the laboratory on two further occasions within 7 days of the final familiarisation trial without undergoing any dietary supplementation (the control trials), with these two tests being separated by 48 hours recovery. Thereafter, participants were assigned to receive two separate 16-day supplementation periods with either a watermelon juice concentrate or an apple juice concentrate as a placebo to complete the experimental testing. During these laboratory visits, blood pressure, muscle oxygenation, pulmonary $\dot{V}_{\mathrm{O}_{2}}$ kinetics and exercise performance were assessed, and a resting venous blood sample was obtained. The supplements were administered orally in a counter-balanced order as part of a double blind, cross-over experimental design. Each supplementation period was separated by 7-10 days of washout. Subjects were required to complete a food diary for the control trials. Specifically, they were asked to record food and drink intake for 5 days, starting two days prior to the first 
control trial and ending on the day of the final control trial. They were provided with a list of foods rich in nitrate and asked to avoid these foods whilst completing the food diary to avoid a potential confounding influence of dietary nitrate intake on the physiological and performance measurements completed in this study [43]. Subjects were instructed to replicate their diet for the final 5 days of the subsequent supplementation periods. The subjects were naive to the experimental hypotheses and were informed that this study sought to investigate the effects of supplementation with two fruit juices on exercise performance.

\subsection{Incremental Test}

During the first laboratory visit subjects completed a ramp incremental cycle test on an electronically-braked cycle ergometer (Lode Excalibur Sport, Groningen, the Netherlands). Initially, subjects performed 3 min of baseline cycling at $20 \mathrm{~W}$, after which the work rate was increased by $30 \mathrm{~W} / \mathrm{min}$ until exhaustion. The subjects cycled at a self-selected pedal rate (70$90 \mathrm{rpm}$ ) and this pedal rate along with saddle and handle bar height and configuration was recorded and reproduced in subsequent tests. Breath-by-breath pulmonary gas-exchange data were collected continuously during the incremental tests and averaged over consecutive 10-s periods. The $\hat{V}_{0_{2 p e a k}}$ was taken as the highest 30 -s mean value attained prior to the subject's volitional exhaustion in the test. The gas exchange threshold was determined from a cluster of measurements including 1$)$ the first disproportionate increase in $\mathrm{CO}_{2}$ production $\left(\dot{V} \mathrm{CO}_{2}\right)$ from visual inspection of individual plots of $\dot{V} \mathrm{CO}_{2}$ Vs. $\left.\dot{V} \mathrm{O}_{2}, 2\right)$ an increase in expired ventilation $\left(\dot{V}_{\mathrm{E}}\right) / \dot{V}_{\mathrm{O}}$ with no increase in $\dot{V}_{\mathrm{E}} / \dot{V}_{\mathrm{CO}_{2}}$, and 3) an increase in end-tidal $\mathrm{O}_{2}$ tension with no fall in end-tidal $\mathrm{CO}_{2}$ tension. The work rates that would require $90 \%$ of the gas exchange threshold (moderate-intensity exercise) and 70\% $\Delta$ (gas exchange threshold plus $70 \%$ of the difference between the work rate at the gas exchange threshold and ${ }^{\circ} \mathrm{O}_{2 \text { peak }}$; severe-intensity exercise) were subsequently calculated with account taken of the mean response time for $\dot{V}_{2}$ during ramp exercise (i.e., two thirds of the ramp rate was deducted from the work rate at gas exchange threshold and peak).

\subsection{Familiarization Tests}

To avoid any order effect on the performance results as a consequence of a potential 'learning effect', subjects were familiarised with all performance tests prior to the experimental testing. Subjects completed a severe-intensity step exercise test terminating with an all-out effort (exercise performance test) followed, after a 45 min passive recovery period, by a severe- 
intensity constant-work-rate step exercise test that was continued until exhaustion (time-toexhaustion test).

\subsection{Supplementation Procedures}

In addition to the unsupplemented control trials, experimental testing was conducted during separate 16-day supplementation periods with watermelon juice and placebo (supplied by Cobell, Exeter, United Kingdom). The watermelon juice and placebo juice concentrates provided $259 \mathrm{kcal}, 1.3 \mathrm{~g}$ protein, $61.8 \mathrm{~g}$ carbohydrate (as sugar), $0.025 \mathrm{~g}$ fat (6.4 mg as saturated fatty acids), $0.075 \mathrm{~g}$ dietary fibre and $42.2 \mathrm{mg}$ sodium per $100 \mathrm{~g}$ of juice. A sample from the batch of watermelon juice used was sent to AltaBioscience (Building Y10, University of Birmingham, Birmingham, United Kingdom) for determination of its amino acid content via ion exchange chromatography. The analysis revealed that watermelon juice contained $11.4 \mathrm{~g}$ L-citrulline and $1.39 \mathrm{~g}$ L-arginine per litre of juice. On days 1-13 and 15 of watermelon juice and placebo supplementation (when participants did not complete any experimental testing), participants were instructed to mix $150 \mathrm{ml}$ of juice with $500 \mathrm{ml}$ water in the morning and late afternoon/evening and to consume slowly over a few hours. On days 14 and 16 of watermelon juice and placebo supplementation (when participants underwent the experimental testing procedures), participants were instructed to mix $150 \mathrm{ml}$ of juice with $500 \mathrm{ml}$ water 3 hours and 1 hour before reporting to the laboratory and to ensure all juice had been ingested 45 min minutes prior to arriving at the laboratory. Therefore, participants received a daily L-citrulline dose of $\sim 3.4 \mathrm{~g}$ during the watermelon juice supplementation period.

\subsection{Experimental Tests}

After reporting to the laboratory, subjects were required to rest in a seated position for $10 \mathrm{~min}$ in an isolated room. Thereafter, blood pressure and pulse rate of the brachial artery was measured using an automated sphygmomanometer (Dinamap Pro, GE Medical Systems, Tampa, USA) whilst the subject was seated. Five measurements were taken and the mean of the measurements was calculated. A venous blood sample was then drawn into a lithiumheparin tube and centrifuged at $4000 \mathrm{rpm}$ and $4^{\circ} \mathrm{C}$ for $10 \mathrm{~min}$, within $3 \mathrm{~min}$ of collection. Plasma was subsequently extracted and immediately frozen at $-80^{\circ} \mathrm{C}$ for later analysis of [nitrite] via chemiluminescence [43], and [L-arginine] and [L-citrulline] via high-performance liquid chromatography (see below for details). The resting pulse rate, blood pressure and 
plasma data are expressed as the mean values collected on the two visits for the control, watermelon juice and placebo trials.

Thirty minutes after arriving at the laboratory (75 minutes after the ingestion of the supplement), subjects completed a series of cycle exercise tests. We elected to commence exercise testing 75 minutes after supplement consumption as the performance trials would then commence $\sim 90$ minutes after supplement consumption, which published pharmacokinetic data has shown coincides with peak plasma [L-arginine] after orally ingesting 3 g L-citrulline [19]. The exercise protocol consisted of two 'step' exercise tests including one moderate-intensity step test followed by one severe-intensity exercise bout. Therefore, all subjects performed a total of two bouts of moderate-intensity exercise and two bouts of severe-intensity exercise for each experimental condition.

Each transition began with 3 min of baseline cycling at $20 \mathrm{~W}$ before an abrupt transition to the target work rate. A passive recovery of 5 min separated the transitions. The moderateintensity steps were each of 4 min duration. On the first control visit and on day 14 of each supplementation trial, subjects cycled at a severe-intensity constant-work-rate $(70 \% \Delta)$ until exhaustion (see Figure 1 for a schematic of this experimental protocol). The time-toexhaustion was recorded when the pedal rate fell by $>10 \mathrm{rpm}$ below the required pedal rate. On day 16 of the supplementation period, subjects cycled for $6 \mathrm{~min}$ at a severe-intensity constant-work-rate $(70 \% \Delta)$ followed immediately by a 30 s all-out effort (see Figure 1 for a schematic of this experimental protocol). The resistance on the pedals during the $30 \mathrm{~s}$ all-out effort was set using the linear mode of the Lode ergometer so that the subject would attain the power output calculated to be $50 \% \Delta$ if they attained their preferred cadence (linear factor $=$ power/preferred cadence ${ }^{2}$ ). Subjects were provided with a $5 \mathrm{~s}$ countdown prior to the all-out effort and were instructed to attain peak power as quickly as possible and to continue exercising maximally for the duration of the all-out effort. No time feedback was given to the subjects at any point during the all-out effort.

\subsection{Measurements}

During all tests, pulmonary gas exchange and ventilation were measured breath-by-breath with subjects wearing a nose clip and breathing through a low-dead-space, low-resistance mouthpiece and impeller turbine assembly (Jaeger Triple V). The inspired and expired gas 
volume and gas concentration signals were continuously sampled at $100 \mathrm{~Hz}$, the latter using paramagnetic $\left(\mathrm{O}_{2}\right)$ and infrared $\left(\mathrm{CO}_{2}\right)$ analyzers (Jaeger Oxycon Pro, Hoechberg, Germany) via a capillary line connected to the mouthpiece. The gas analyzers were calibrated before each test with gases of known concentration and the turbine volume transducer was calibrated with a 3-liter syringe (Hans Rudolph, Kansas City, MO). The volume and concentration signals were time-aligned by accounting for the delay in the capillary gas transit and the analyzer rise time relative to the volume signal. Pulmonary gas exchange and ventilation were calculated and displayed breath-by-breath. The pulmonary $\dot{V}_{\mathrm{O}_{2}}$ responses in the two moderate-intensity and severe-intensity step tests in control, watermelon juice and placebo were averaged to improve the signal-to-noise ratio and the confidence surrounding the estimation of the $\hat{V}_{\mathrm{O}_{2}}$ kinetic parameters obtained from the exponential modelling procedures [44] (see Data Analysis Procedures below).

During the exercise trials, a blood sample was collected from a fingertip into a capillary tube over the $20 \mathrm{~s}$ preceding the step transition in work rate, the $20 \mathrm{~s}$ preceding the completion of 240 s of moderate cycling exercise and 360 s severe cycling exercise, and also immediately following the all-out effort and immediately after exhaustion during the severe-intensity constant-work-rate trial. These whole blood samples were subsequently analyzed to determine blood [lactate] and [glucose] (YSI 2300, Yellow Springs Instruments, Yellow Springs, $\mathrm{OH}$, United States) within $30 \mathrm{~s}$ of collection.

The oxygenation status of the $m$. vastus lateralis of the right leg was monitored using a commercially available near-infrared spectroscopy system (model NIRO 300, Hamamatsu Photonics KK, Hiugashi-ku, Japan). The system consisted of an emission probe that irradiates laser beams and a detection probe. Four different wavelength laser diodes provided the light source (776, 826, 845, and $905 \mathrm{~nm}$ ) and the light returning from the tissue was detected by a photomultiplier tube in the spectrometer. The intensity of incident and transmitted light was recorded continuously at $2 \mathrm{~Hz}$ and used to estimate concentration changes from the resting baseline for oxygenated, deoxygenated, and total tissue hemoglobin/myoglobin. Therefore, the near-infrared spectroscopy data represent a relative change based on the optical density measured in the first datum collected. It should be noted here that the contribution of deoxygenated myoglobin to the near-infrared spectroscopy signal is presently unclear, and, as such, the terms [oxyhemoglobin], and [deoxyhemoglobin] used in this paper should be considered to refer to the combined concentrations of oxygenated 
and deoxygenated hemoglobin and myoglobin, respectively. The tissue oxygenation index (TOI) was calculated using the following equation:

Tissue oxygenation index $=\frac{[\text { oxyhemoglobin }]}{\text { [oxyhemoglobin] }+ \text { [deoxyhemoglobin }]} \times 100$

The leg was initially cleaned and shaved around the belly of the muscle, and the optodes were placed in the holder, which was secured to the skin with adhesive at $20 \mathrm{~cm}$ above the fibular head. To secure the holder and wires in place, an elastic bandage was wrapped around the subject's leg. The wrap helped to minimize the possibility that extraneous light could influence the signal and also ensured that the optodes did not move during exercise. Indelible pen marks were made around the holder to enable precise reproduction of the placement in subsequent tests. The probe gain was set with the subject at rest in a seated position with the leg extended at down stroke on the cycle ergometer before the first exercise bout, and nearinfrared spectroscopy data were collected continuously throughout the exercise protocols. The data were subsequently downloaded onto a personal computer, and the resulting text files were stored on disk for later analysis.

Plasma [L-arginine] and [L-citrulline] were determined by o-phthaldialdehyde (OPA) derivatised, fluorescence-detection HPLC, using methods adapted from Jones and Gilligan [45]. The high-performance liquid chromatography apparatus was a Perkin Elmer Flexar LC system with Chromera software (Perkin Elmer, MASS, USA). In brief, plasma was deproteinised in $1.5 \mathrm{~N}$ perchloric acid, neutralised in $2 \mathrm{~N}$ potassium hydrogen carbonate, and centrifuged. $100 \mu \mathrm{L}$ of supernatant, $100 \mu \mathrm{L}$ of $1.2 \%$ benzoic acid, and $1.4 \mathrm{~mL} \mathrm{H}_{2} \mathrm{O}$ were added to high-performance liquid chromatography vials. $50 \mu \mathrm{L}$ of unknowns/standards were mixed with $50 \mu \mathrm{L}$ of an OPA solution containing 2-mercaptoethanol (fluoraldehyde $o$ phthaldialdehyde reagent solution, Thermo Scientific, IL, USA), enabling the pre-column derivatization of amino acids with a highly fluorescent $o$-phthaldialdehyde adduct. $25 \mu \mathrm{L}$ of derivatised sample was mixed in mobile phase and eluted at $0.8 \mathrm{ml} \mathrm{min}^{-1}$ through a $4.6 \mathrm{x} 150$ mm, $2.7 \mu \mathrm{m}$ Brownlee SPP C18 reverse-phase analytical column with $5 \mathrm{~mm}$ guard column with matching specification. A gradient protocol of aqueous mobile phase A $(0.05 \mathrm{M}$ potassium phosphate buffer, $\mathrm{pH}$ 7.2) with organic mobile phase $\mathrm{B}$ (acetonitrile/methanol/water, 40/40/20) was performed: 0 - $1.5 \mathrm{~min}, 80 \%$ Mobile A; 1.5 18.5, 80 - 65\%; 23.5, 50\%; 32.5, 40\%; 36.5, 30\%; 43.5, 0\%; 51.5, 80\%. Fluorescence was 
monitored at excitation and emission wavelengths of 340 and $455 \mathrm{~nm}$, respectively. Amino acid concentrations were determined against standard curves between 0 and $500 \mu \mathrm{M}$.

\subsection{Data Analysis Procedures}

The breath-by-breath $\dot{V}_{\mathrm{O}_{2}}$ data from each test were initially examined to exclude errant breaths caused by coughing, swallowing, sighing, etc., and those values lying more than four standard deviations from the local mean were removed. The breath-by-breath data were subsequently linearly interpolated to provide second-by-second values and, for each individual, the two moderate-intensity and two severe-intensity repetitions were time-aligned to the start of exercise and ensemble-averaged. For moderate-intensity exercise, baseline and end-exercise $\dot{V}_{\mathrm{O}_{2}}$ were taken as the mean $\dot{V}_{\mathrm{O}_{2}}$ over the 90 s preceding the step transition and the mean $\dot{V}_{2}$ over the final $60 \mathrm{~s}$ of the step transition, respectively. For severe-intensity exercise, the first $20 \mathrm{~s}$ of data after the onset of exercise (i.e., the phase I response) were deleted and a nonlinear least-square algorithm was used to fit the data thereafter. A biexponential model was used to characterize the $\dot{V}_{\mathrm{O}_{2}}$ responses to severe-intensity exercise, as described in the following equation:

$\dot{V}_{\mathrm{O}_{2}}(\mathrm{t})=\dot{V}_{\mathrm{O}_{2}}$ baseline $+\mathrm{A}_{\mathrm{p}}\left(1-\mathrm{e}^{-(\mathrm{t}-\mathrm{TDp} / \tau \mathrm{p})}\right)+\mathrm{A}_{\mathrm{s}}\left(1-\mathrm{e}^{-(\mathrm{t}-\mathrm{TDs} / \tau \mathrm{s})}\right)$

where $\dot{V} \mathrm{O}_{2}(t)$ represents the absolute $\dot{V}_{\mathrm{O}_{2}}$ at a given time $t ; \dot{V} \mathrm{O}_{2}$ baseline represents the mean $\dot{V} \mathrm{O}_{2}$ in the baseline period; $\mathrm{A}_{\mathrm{p}}, \mathrm{TD}_{\mathrm{p}}$, and $\tau_{\mathrm{p}}$ represent the amplitude, time delay, and time constant, respectively, describing the phase II increase in $\dot{V}_{\mathrm{O}_{2}}$ above baseline; and $\mathrm{A}_{\mathrm{s}}$, $\mathrm{TD}_{\mathrm{s}}$, and $\tau_{\mathrm{s}}$ represent the amplitude of, time delay before the onset of, and time constant describing the development of, the $\dot{V}_{\mathrm{O}_{2}}$ slow component, respectively.

In addition, a single-exponential model without time delay, with the fitting window commencing at $t=0 \mathrm{~s}$ (equivalent to the mean response time), was used to characterize the kinetics of the overall $\hat{V}_{2}$ response during the trials as described in the following equation:

$\dot{V}_{\mathrm{O}_{2}}(\mathrm{t})=\dot{V} \mathrm{O}_{2}$ baseline $+\mathrm{A}\left(1-\mathrm{e}^{-\mathrm{t} / \mathrm{MRT})}\right)$

An iterative process was used to minimize the sum of the squared errors between the fitted function and the observed values. $\dot{V} \mathrm{O}_{2}$ baseline was defined as the mean $\dot{V} \mathrm{O}_{2}$ measured over the final $90 \mathrm{~s}$ of the resting baseline period. The $\dot{V}_{\mathrm{O}_{2}}$ at $360 \mathrm{~s}$ was taken as the mean $\dot{V}_{\mathrm{O}_{2}}$ between 
330 and 360 s, the $\dot{V}_{2}$ at exhaustion was taken as the mean $\dot{V}_{2}$ measured over the final $30 \mathrm{~s}$ of the exhaustive exercise bout, and the $\dot{V}_{2}$ at the end of the all-out effort was taken as the mean $\dot{V}_{\mathrm{O}_{2}}$ measured over the final $15 \mathrm{~s}$ of the all-out effort. Because the asymptotic value $\left(\mathrm{A}_{\mathrm{s}}\right)$ of the exponential term describing the $\dot{V}_{\mathrm{O}_{2}}$ slow component may represent a higher value than is actually reached at the end of the exercise, the actual amplitude of the $\dot{V}_{\mathrm{O}_{2}}$ slow component at the end of exercise was defined as $A_{s}$ '. The $A_{s}$ ' parameter was compared at the same iso-time (360-s) for all dietary interventions. The near-infrared spectroscopy-derived TOI was assessed at baseline (90-s mean preceding step transition) and end-exercise (mean response over the final $30 \mathrm{~s}$ of exercise).

\subsection{Statistics}

A one-way repeated-measures ANOVA was employed to assess between-supplement differences in blood pressure and heart rate; blood [glucose] and [lactate]; plasma [L-arginine], [L-citrulline] and [nitrite]; pulmonary $\dot{V}_{\mathrm{O}_{2}}$; near-infrared spectroscopy-derived tissue oxygenation index; and exercise performance indices. Significant effects were further explored using simple contrasts with Fisher's LSD. Data are presented as mean \pm SD, unless otherwise stated. Statistical significance was accepted when $P<0.05$. Effect size was calculated as Cohen's $d$.

\section{Results}

On the days of the experimental testing, all participants reported mild gastrointestinal (GI) discomfort with symptoms of mild stomach cramps and/or flatulence with both the watermelon juice and placebo supplements. All participants consumed at least $95 \%$ of the required supplement portions and their diet was consistent in the days surrounding each of the intervention periods. In the ramp incremental test, participants attained a peak power output of $360 \pm 61 \mathrm{~W}$ and a $\dot{V} \mathrm{O}_{2 \text { peak }}$ of $4.11 \pm 0.71 \mathrm{~L} \cdot \mathrm{min}^{-1}\left(52 \pm 8 \mathrm{ml} \cdot \mathrm{kg}^{-1} \cdot \mathrm{min}^{-1}\right)$. The work rates applied during the moderate-intensity and severe-intensity step tests were $112 \pm 22 \mathrm{~W}$ and $274 \pm 54 \mathrm{~W}$, respectively.

\section{Plasma [L-citrulline], [L-arginine], and $\left[\mathrm{NO}_{2}^{-}\right]$}

The plasma [L-citrulline], [L-arginine], and $\left[\mathrm{NO}_{2}{ }^{-}\right]$in the CON, WMJ and PLA conditions are illustrated in Figure 2. There was a significant main effect for supplement on plasma [L- 
citrulline], [L-arginine], and [nitrite]. Plasma [L-citrulline] was higher in the watermelon juice condition $(101 \pm 23 \mu \mathrm{M})$ compared to the placebo $(22 \pm 6 \mu \mathrm{M})$ and control $(29 \pm 4 \mu \mathrm{M})$ conditions $(P<0.001)$, with plasma [L-citrulline] being lower with PLA than CON $(P<0.05$; Figure 2). Plasma [L-arginine] was higher in the watermelon juice condition (116 $\pm 9 \mu \mathrm{M})$ compared to the placebo $(67 \pm 13 \mu \mathrm{M})$ and control $(74 \pm 9 \mu \mathrm{M})$ conditions $(P<0.001)$, with no significant differences between plasma [L-arginine] in the placebo and control trials ( $P>0.05$; Figure 2). Similarly, plasma [nitrite] was higher in the watermelon juice condition (201 $\pm 106 \mathrm{nM})$ compared to the placebo $(106 \pm 21 \mathrm{nM})$ and control $(102 \pm 29 \mathrm{nM})$ conditions $(P<0.05)$, with no significant differences in plasma [nitrite] between the placebo and control trials $(P>0.05$; Figure 2$)$.

\section{Blood pressure and heart rate}

There was a significant main effect for supplement on heart rate, systolic blood pressure and mean arterial pressure (all $P<0.05$ ), but not diastolic blood pressure $(P>0.05)$. Heart rate, systolic blood pressure and mean arterial pressure were higher in both watermelon juice and placebo compared to the control condition $(P<0.05$; Table 1$)$. These variables were not different between the watermelon juice and placebo conditions ( $P>0.05$; Table 1$)$.

\section{Tissue oxygenation index}

The tissue oxygenation index in the control, watermelon juice and placebo conditions during moderate-intensity and severe-intensity cycling exercise is illustrated in Figure 3. There was a significant main effect for supplement on the change ( $\Delta$ end-start) in tissue oxygenation index during moderate-intensity exercise $(P<0.05)$. Further analysis revealed that tissue oxygenation declined by a smaller magnitude during moderate-intensity exercise in the watermelon juice condition compared to the placebo and control conditions $(P<0.05$; Figure 3). There were no between-condition differences in tissue oxygenation index during baseline cycling $(P>0.05)$, but the tissue oxygenation index at end-exercise was higher in the watermelon juice condition that the placebo condition $(P<0.05$; Figure 3$)$. There were no significant differences between the experimental conditions in tissue oxygenation index at baseline or end-exercise during the severe-intensity exercise test $(P>0.05$; Figure 3$)$.

\section{Pulmonary $\dot{\mathrm{V}} \mathrm{O}_{2}$}

There were no significant differences in pulmonary $\dot{V}_{2}$ at baseline or end-exercise during the moderate-intensity step exercise tests between the three experimental conditions $(P>0.05$; 
Table 2). Likewise, there were no differences in pulmonary $\dot{V}_{\mathrm{O}_{2}}$ at baseline, $360 \mathrm{~s}$, the end of the all-out effort or exhaustion during the severe-intensity step exercise tests between the three experimental conditions ( $P>0.05$; Table 2). Moreover, phase II $\dot{V} \mathrm{O}_{2}$ kinetics and the $\dot{V}$ $\mathrm{O}_{2}$ fundamental and slow component amplitudes were not significantly different between the three experimental conditions ( $P>0.05$; Table 2$)$.

\section{Blood [glucose] and [lactate]}

There were no significant between-condition differences in blood [glucose] at any point of the moderate-intensity and severe-intensity step exercise tests. In contrast, there were significant main effects for condition on baseline and end-exercise blood [lactate] during the moderate-intensity step tests $(P<0.05)$. The baseline blood [lactate] during the moderateintensity step test was higher with both watermelon juice and placebo supplementation compared to the control condition $(P<0.05)$, while end-exercise blood [lactate] was higher than the control condition after placebo supplementation $(P<0.05$; Table 3$)$. The ANOVA indicated a significant main effect for condition on baseline blood [lactate] during the severeintensity step test $(P<0.05)$, with baseline blood [lactate] being higher than the control condition after watermelon juice and placebo supplementation $(P<0.05$; Table 3$)$. There was no significant main effect for condition on blood [lactate] at any other time point during the severe-intensity exercise test $(P>0.05$; Table 3$)$.

\section{Exercise performance}

The power output during the $30 \mathrm{~s}$ all-out effort in the control, watermelon juice and placebo conditions is illustrated in Figure 4. There was no significant main effect for condition on either the peak power output or total work done in the $30 \mathrm{~s}$ all-out effort $(P>0.05)$. However, there was a significant main effect for condition on the total work done over the first $10 \mathrm{~s}$ of the all-out effort $(P<0.05$; Figure 4). Follow-up analyses indicated that the total work done over the first $10 \mathrm{~s}$ of the all-out effort was higher in the watermelon juice condition $(4.7 \pm 1.7$ $\mathrm{kJ}$ ) compared to the control condition ( $4.2 \pm 1.4 \mathrm{~kJ}$; $P<0.05$; Table 4; Figure 4), but not the placebo condition ( $4.5 \pm 1.6 \mathrm{~kJ} ; P>0.05)$. There was no significant main effect for condition on the time to exhaustion during the severe-intensity constant work rate exercise test $(P>0.05$; Table 4$)$. 


\section{Discussion}

The important novel finding from this study is that chronic supplementation with a watermelon juice concentrate, which provided a daily L-citrulline dose of $\sim 3.4 \mathrm{~g}$ and increased plasma [L-citrulline] and [L-arginine], also increased the sensitive biomarker of nitric oxide synthase activity, plasma [nitrite]. In addition, muscle oxygenation during moderate-intensity exercise was increased after watermelon juice supplementation. However, in spite of a significant increase in plasma [nitrite], watermelon juice increased resting blood pressure and heart rate above values observed in the unsupplemented control condition. Muscle oxygenation and performance during severe-intensity exercise, and pulmonary $\dot{V}_{\mathrm{O}_{2}}$ during moderate-intensity and severe-intensity exercise were not significantly impacted by watermelon juice supplementation. Therefore, the results of this study suggest that, while chronic watermelon juice supplementation has the potential to increase nitric oxide synthesis, this benefit is somewhat offset by an increase in resting blood pressure and heart rate. Moreover, given that severe-intensity exercise performance was not improved following watermelon juice supplementation, our findings do not support the use of watermelon juice as a nutritional aid to improve endurance exercise performance in recreationally-active participants.

It is well documented that watermelon juice is rich in L-citrulline $[28,30,34,46,47]$ and that orally ingested L-citrulline readily passes into the systemic circulation [48]. Consistent with this, 16 days supplementation with $300 \mathrm{~mL} \cdot$ day $^{-1}$ of a watermelon juice concentrate, which provided $3.4 \mathrm{~g}$ L-citrulline·day ${ }^{-1}$, increased plasma [L-citrulline] 3-4 fold above values observed in the placebo condition. The two previous studies that have measured plasma [Lcitrulline] following watermelon juice ingestion have reported conflicting findings. Specifically, Mandel et al. [29] observed a 26 fold increase in plasma [L-citrulline] after the acute consumption of $3.3 \mathrm{~kg}$ (wet weight) watermelon (L-citrulline content not quantified), whereas plasma [L-citrulline] was not increased after consuming $780 \mathrm{~g}$ ( $1 \mathrm{~g}$ L-citrulline) or 1560 g ( 2 g L-citrulline) of watermelon juice day $^{-1}$ for 3 weeks in the study by Collins et al. [30]. These inter-study differences might be linked to differences in the watermelon supplementation procedures employed and the L-citrulline doses administered. However, while the effect of watermelon consumption on plasma [L-citrulline] is equivocal, plasma [Larginine] was increased in the current study (+42\%), as well as the studies by Mandel et al. 
[29] (+2 fold) and Collins et al. [30] (+10\% with the lower dose; $+25 \%$ with the higher dose) compared to the respective placebo/control conditions. Following oral ingestion, circulating L-citrulline is taken up by a number of tissues and subsequently converted, via the stepwise activity of the enzymes, arginoinosuccinate synthase and arginoinosuccinate lyase, to Larginine $[17,49,50]$. Therefore, the findings of this study suggest that chronic watermelon juice supplementation can increase the circulating L-arginine pool and, by extension, substrate for nitric oxide synthase.

In addition to increasing substrate provision for nitric oxide synthase, we observed an increase in the circulating plasma [nitrite] after watermelon juice supplementation. There is evidence to suggest that the plasma [nitrite] sensitively reflects endothelial nitric oxide synthase activity [32] and that L-citrulline supplementation can increase nitric oxide synthase activation [20] and nitric oxide biomarkers [19,21]. The greater plasma [nitrite] after watermelon juice supplementation in this study therefore suggests that watermelon juice supplementation was effective at increasing nitric oxide synthase-derived nitric oxide. A previous study has reported that nitric oxide synthase activity and plasma [NOx] ([nitrate] + [nitrite]) were increased after 4 weeks supplementation with watermelon pomace in Zucker diabetic fatty rats [31], but the current study is the first, to our knowledge, to suggest that watermelon juice supplementation can increase nitric oxide production through nitric oxide synthase in humans. In a recent study, we reported that seven days supplementation with $6 \mathrm{~g}$ L-citrulline day $^{-1}$ (total L-citrulline dose of $42 \mathrm{~g}$ ) did not significantly increase plasma [nitrite], but the 21\% increase did approach statistical significance [22]. However, when a similar total L-citrulline dose was administered as concentrated watermelon juice in this study, plasma [nitrite] was increased by $90 \%$ in spite of a lower increase in plasma [Larginine] (+42\%) compared to our previous study (+137\%) [22]. The greater potential for nitric oxide synthesis after watermelon juice supplementation might be linked to a synergistic effect between L-citrulline and other constituents of watermelon juice. For example, watermelon juice is high in the non-enzyme antioxidants, glutathione, lycopene and $\beta$ carotene [34-36], which can scavenge the superoxide radical [37,51]. This is important given the rapid reaction of superoxide with nitric oxide to form peroxynitrite which compromises nitric oxide bioavailability [52]. Importantly, watermelon juice supplementation has been shown to increase plasma [lycopene] and [ $\beta$-carotene] [35] and recent evidence suggests that concurrent supplementation with L-citrulline and glutathione is more effective at increasing nitric oxide biomarkers than independent supplementation with L-citrulline [33]. Taken 
together, these findings suggest that watermelon juice supplementation might represent an effective nutritional intervention to increase nitric oxide production and bioavailability.

Pulmonary $\dot{V}_{\mathrm{O}_{2}}$ during moderate-intensity exercise was not significantly impacted by watermelon juice supplementation in this study. It has recently been reported that increasing the circulating plasma [nitrite] via nitrate-rich beetroot juice supplementation can lower $\dot{V}_{\mathrm{O}_{2}}$ during moderate-intensity exercise [e.g., 43]. However, plasma [nitrite] was only increased by $90 \%$ after watermelon juice supplementation in this study and a reduction in $\dot{V}_{\mathrm{O}_{2}}$ during moderate-intensity exercise is only typically observed after nitrate-rich beetroot juice supplementation when plasma [nitrite] is increased at least 2 fold above baseline when using the same plasma [nitrite] assay (ozone-based chemiluminescence analysis of nondeproteinised plasma) used in this study [43]. Therefore, the increase in nitric oxide synthesis after watermelon juice supplementation in this study was likely insufficient to evoke an improvement in cycling economy. However, while the $\mathrm{O}_{2}$ cost of moderateintensity exercise was not altered after watermelon juice supplementation, muscle oxygenation during moderate-intensity was greater following watermelon juice supplementation. Indices of muscle oxygenation were also improved in our recent study after L-citrulline supplementation [22]. Taken together, these findings suggest that supplementation with watermelon juice or L-citrulline may improve the balance between muscle $\mathrm{O}_{2}$ supply and muscle $\mathrm{O}_{2}$ demand during moderate-intensity exercise.

In contrast to our recent study with L-citrulline supplementation [22], time-to-exhaustion and the total work completed during the all-out effort were not improved after watermelon juice supplementation compared to placebo in this study. Two other recent studies have also observed no improvement in exercise performance indices after watermelon juice supplementation [28,42]. In our previous study where L-citrulline was ergogenic, we observed improved muscle oxygenation and faster $\dot{V}_{\mathrm{O}_{2}}$ kinetics and attributed the ergogenic effects of L-citrulline to an increase in proportional energy contribution from oxidative metabolism [22]. Previous studies have also reported improved muscle function after Lcitrulline supplementation when oxidative metabolism is improved [23,24]. However, pulmonary $\dot{V} \mathrm{O}_{2}$ kinetics and muscle oxygenation during severe-intensity exercise were not improved by watermelon juice supplementation in this study and exercise performance was unaltered. Collectively, these observations suggest that increasing dietary L-citrulline intake has the potential to improve endurance exercise performance only when indices of aerobic 
metabolism are improved. The improvements in muscle force production/fatigue resistance after studies administering L-citrulline powder [22,23] compared to the lack of improvements in muscle performance after watermelon juice [28,42, the current study] might be linked to the greater L-citrulline doses administered in the studies administering L-citrulline powder. To our knowledge, this study has assessed exercise performance variables after the largest Lcitrulline dose administered via watermelon juice. Given that exercise performance was not enhanced with a watermelon juice concentrate in this study, our findings suggest that watermelon juice supplementation is unlikely to represent an ergogenic aid for endurance performance. We observed that watermelon juice supplementation and the apple juice placebo tended to increase time-to-exhaustion compared to the control condition. This might be linked to the chronic carbohydrate consumption in both the juice concentrate conditions compared to the control conditions [53]. There is also evidence that chronic carbohydrate consumption does not improve performance during short-duration high-intensity exercise [see 54 for review] and the general consensus is that carbohydrate supplementation is not necessary to optimise performance during events $<30 \mathrm{~min}$ in duration [55].

While watermelon juice supplementation offers promise as a nutritional intervention to increase nitric oxide bioavailability and muscle oxygenation during moderate-intensity exercise, there were some negative side effects associated with the watermelon juice supplementation regime used in this study. Firstly, participants reported mild gastrointestinal discomfort after watermelon juice supplementation that was manifest as mild stomach cramps and/or flatulence. Since similar side effects were reported with placebo supplementation, and since previous studies administering a similar L-citrulline dose to that ingested in this study have reported no side effects [e.g., 19], the gastrointestinal discomfort after watermelon juice supplementation in this study is unlikely to be a consequence of L-citrulline ingestion per se. Gastrointestinal discomfort can be provoked by high fat, fibre or protein consumption, or the ingestion of a concentrated carbohydrate solution [56]. The watermelon juice and placebo supplements were low in fat (0.025 g/100 g juice), fibre (0.075 g/100 g juice) and protein (1.3 $\mathrm{g} / 100 \mathrm{~g}$ juice), but high in carbohydrate (61.8 g sugar/100 g juice). As such, the gastrointestinal discomfort reported after watermelon juice and placebo ingestion is likely to have arisen as a consequence of the high sugar content of the watermelon juice and placebo supplements. Secondly, blood pressure and heart rate were increased after watermelon juice supplementation. This conflicts with recent observations that supplementation with watermelon juice can lower blood pressure in hypertensive participants [38-41]. Blood 
pressure and heart rate were increased above the unsupplemented control condition by a similar magnitude after watermelon juice and placebo supplementation. This suggests that the high sugar intake with the watermelon juice and placebo supplements might also have played a role in increasing blood pressure and heart rate. Previous studies have also observed an increase in blood pressure after the consumption of beverages rich in sugar [e.g., 57]. Although the mechanism for the increase in blood pressure following the consumption of sugar-enriched beverages is not entirely clear, there is some evidence that increased sugar intake can increase sympathetic nervous system activity [58]. Therefore, the increased blood pressure after watermelon juice and placebo supplementation in this study might be linked to an increase in sympathetic drive. The increase in resting heart rate after watermelon juice and placebo supplementation in this study is consistent with this interpretation. Given the increased stress placed on the cardiovascular system after watermelon juice consumption in this study, and the increase in coronary heart disease and hypertension morbidity associated with the consumption of sugar-sweetened beverages [59], longer term supplementation with a watermelon juice concentrate, at least in the form administered in this study, cannot be recommended.

Although the watermelon juice concentrate administered in this study was not ergogenic for endurance exercise performance and evoked negative cardiovascular responses, it is known that the L-citrulline content of watermelon varies by the watermelon variety [46] and that the rind of a watermelon contains more L-citrulline than the flesh of the fruit [46,47]. Therefore, we acknowledge that it might have been possible to consume a lower volume of watermelon juice (with a corresponding reduction in sugar intake) to attain the same or a larger Lcitrulline dose to that administered in the current study if a different watermelon variety had been used or more of the rind was incorporated into the watermelon juice. Administering a sugar-free/reduced sugar watermelon juice concentrate might also hold promise given that watermelon juice appears to be more effective at increasing nitric oxide production (the current study) compare to an equivalent total dose of pure L-citrulline [22]. Further research is required to assess the effects of a sugar-free/reduced sugar watermelon juice concentrate and lower doses of watermelon juice on nitric oxide production, vascular and metabolic function, and functional capacity in healthy adults, as well as patients with vascular and metabolic diseases. 


\section{Conclusion}

In conclusion, 14-16 days supplementation with a watermelon juice concentrate, that provided $3.4 \mathrm{~g} \mathrm{~L}$-citrulline· day $^{-1}$, increased plasma [nitrite]. This suggests increased nitric oxide production through nitric oxide synthase. During moderate-intensity exercise pulmonary $\dot{V}_{\mathrm{O}_{2}}$ was not different but muscle oxygenation was greater after watermelon juice supplementation. This implies that watermelon juice supplementation improved the balance between muscle $\mathrm{O}_{2}$ supply and muscle $\mathrm{O}_{2}$ demand during moderate-intensity exercise. However, watermelon juice supplementation did not improve pulmonary $\dot{V}_{2}$ kinetics, muscle oxygenation or exercise performance indices during severe-intensity cycling exercise. Moreover, participants experienced gastrointestinal discomfort and exhibited increases in resting blood pressure and heart rate after the watermelon juice supplementation regime employed in this study. Therefore, while the results of this study suggest that supplementation with a watermelon juice concentrate can elicit improvements in baseline nitric oxide production and muscle oxygenation during moderate-intensity exercise, severeintensity exercise performance was unaffected, and resting blood pressure and heart rate were increased after watermelon juice supplementation compared to placebo supplementation. These findings do not support the use of watermelon juice supplementation to aid endurance exercise performance and vascular health in healthy adults.

\section{Acknowledgment}

The authors are grateful to Cobell Ltd for providing the watermelon and apple juice concentrates that were used in this study. We received no funding from Cobell Ltd for this work. 


\section{References}

[1] J.S. Stamler, G. Meissner, Physiology of nitric oxide in skeletal muscle, Physiol Rev. 81 (2001) 209-237.

[2] F. Suhr, S. Gehlert, M. Grau, W. Bloch, Skeletal muscle function during exercise-finetuning of diverse subsystems by nitric oxide, Int J Mol Sci. 14 (2013) 7109-7139.

[3] S. Moncada, E.A. Higgs, Endogenous nitric oxide: physiology, pathology and clinical relevance, Eur J Clin Invest. 21 (1991) 361-374.

[4] T.H. Liu, C.L. Wu, C.W. Chiang, Y.W. Lo, H.F. Tseng, C.K. Chang, No effect of shortterm arginine supplementation on nitric oxide production, metabolism and performance in intermittent exercise in athletes, J Nutr Biochem. 20 (2009) 462-468.

[5] J.E. Tang, P.J. Lysecki, J.J. Manolakos, M.J. MacDonald, M.A. Tarnopolsky, S.M. Phillips, Bolus arginine supplementation affects neither muscle blood flow nor muscle protein synthesis in young men at rest or after resistance exercise, J Nutr. 141 (2011) 195200.

[6] R. Bescós, C. Gonzalez-Haro, P. Pujol, F. Drobnic, E. Alonso, M.L. Santolaria, O. Ruiz, M. Esteve, P. Galilea, Effects of dietary L-arginine intake on cardiorespiratory and metabolic adaptation in athletes, Int J Sport Nutr Exerc Metab. 19 (2009) 355-365.

[7] K. Koppo, Y.E. Taes, A. Pottier, J. Boone, J. Bouckaert, W. Derave, Dietary arginine supplementation speeds pulmonary $\dot{V}_{\mathrm{O}_{2}}$ kinetics during cycle exercise, Med Sci Sports Exerc. 41 (2009) 1626-1632.

[8] A. Schaefer, F. Piquard, B. Geny, S. Doutreleau, E. Lampert, B Mettauer, J. Lonsdorfer, $\mathrm{L}$-arginine reduces exercise-induced increase in plasma lactate and ammonia, Int $\mathrm{J}$ Sports Med. 23 (2002) 403-407. 
[9] A. Vanhatalo, S.J. Bailey, F.J. DiMenna, J.R. Blackwell, G.A. Wallis, A.M. Jones, No effect of acute L-arginine supplementation on $\mathrm{O}_{2}$ cost or exercise tolerance, Eur $\mathrm{J}$ Appl Physiol. 113 (2013) 1805-1819.

[10] T.S. Álvares, C.M. Meirelles, Y.N. Bhambhani, V.M. Paschoalin, P.S. Gomes, LArginine as a potential ergogenic aid in healthy subjects, Sports Med. 412011 233-248.

[11] L. Castillo, T.C. deRojas, T.E. Chapman, J. Vogt, J.F. Burke, S.R. Tannenbaum, V.R. Young, Splanchnic metabolism of dietary arginine in relation to nitric oxide synthesis in normal adult man, Proc Natl Acad Sci U S A. 90 (1993) 193-197.

[12] G. Wu, Intestinal mucosal amino acid catabolism, J Nutr. 128 (1998) 1249-1252.

[13] S.M. Jr. Morris, Regulation of enzymes of the urea cycle and arginine metabolism, Annu Rev Nutr. 22 (2002) 87-105.

[14] D. O'sullivan, J.T. Brosnan, M.E. Brosnan, Hepatic zonation of the catabolism of arginine and ornithine in the perfused rat liver, Biochem J. 330 (1998) 627-632.

[15] M.C. van de Poll, M.P. Siroen, P.A. van Leeuwen, P.B. Soeters, G.C. Melis, P.G. Boelens, N.E. Deutz, C.H. Dejong Interorgan amino acid exchange in humans: consequences for arginine and citrulline metabolism, Am J Clin Nutr. 85 (2007) 167-172.

[16] Y.M. Yu, J.F. Burke, R.G. Tompkins, R. Martin, V.R. Young, Quantitative aspects of interorgan relationships among arginine and citrulline metabolism, Am J Physiol. 271 (1996) 1098-1109.

[17] R.J. Haines, L.C. Pendleton, D.C. Eichler, Argininosuccinate synthase: at the center of arginine metabolism, Int J Biochem Mol Biol. 2 (2011) 8-23.

[18] S. Osowska, C. Moinard, N. Neveux, C. Loï, L. Cynober, Citrulline increases arginine pools and restores nitrogen balance after massive intestinal resection, Gut. 53 (2004) 17811786. 
[19] E. Schwedhelm, R. Maas, R. Freese, D. Jung, Z. Lukacs, A. Jambrecina, W. Spickler, F. Schulze, R.H. Böger, Pharmacokinetic and pharmacodynamic properties of oral L-citrulline and L-arginine: impact on nitric oxide metabolism, Br J Clin Pharmacol. 65 (2008) 51-59.

[20] K.A. Wijnands, H. Vink, J.J. Briedé, E.E. van Faassen, W.H. Lamers, W.A. Buurman, M. Poeze, Citrulline a more suitable substrate than arginine to restore NO production and the microcirculation during endotoxemia, PLoS One. 7:e37439 (2012).

[21] M. Ochiai, T. Hayashi, M. Morita, K. Ina, M. Maeda, F. Watanabe, K. Morishita, Shortterm effects of L-citrulline supplementation on arterial stiffness in middle-aged men, Int $\mathrm{J}$ Cardiol. 155 (2012) 257-261.

[22] S.J. Bailey, J.R. Blackwell, T. Lord, A. Vanhatalo, P.G. Winyard, A.M. Jones, Lcitrulline supplementation improves $\mathrm{O}_{2}$ uptake kinetics and high-intensity exercise performance in humans, J Appl Physiol. 119 (2015) 385-395.

[23] D. Bendahan, J.P. Mattei, B. Ghattas, S. Confort-Gouny, M.E. Le Guern, P.J. Cozzone, Citrulline/malate promotes aerobic energy production in human exercising muscle, $\mathrm{Br} \mathrm{J}$ Sports Med. 36 (2002) 282-289.

[24] B. Giannesini, Y. Le Fur, P.J. Cozzone, M. Verleye, M.E. Le Guern, D. Bendahan, Citrulline malate supplementation increases muscle efficiency in rat skeletal muscle, Eur $\mathbf{J}$ Pharmacol. 667 (2011) 100-104.

[25] Y Koga, R Ohtake, Study report on the constituents of squeezed watermelon, Journal of the Tokyo Chemical Society. 35 (1912) 519-528.

[26] M. Wada, On the occurrence of a new amino acid in watermelon, Proceedings of the Imperial Academy. 6 (1930) 15-17.

[27] K. Fragkos, A Forbess, Was citrulline first a laxative substance? The truth about modern citrulline and its isolation, Journal of Japanese history of medicine. 57 (2011) 275-292. 
[28] M.P. Tarazona-Díaz, F. Alacid, M. Carrasco, I. Martínez, E. Aguayo, Watermelon juice: potential functional drink for sore muscle relief in athletes, J Agric Food Chem. 61 (2013) $7522-7528$

[29] H. Mandel, N. Levy, S. Izkovitch, S.H. Korman Elevated plasma citrulline and arginine due to consumption of Citrullus vulgaris (watermelon), J Inherit Metab Dis. 28 (2005) 467472.

[30] J.K. Collins, G. Wu, P. Perkins-Veazie, K. Spears, P.L. Claypool, R.A. Baker, B.A. Clevidence, Watermelon consumption increases plasma arginine concentrations in adults, Nutrition. 23 (2007) 261-266.

[31] G. Wu, J.K. Collins, P. Perkins-Veazie, M. Siddiq, K.D. Dolan, K.A. Kelly, C.L. Heaps, C.J. Meininger, Dietary supplementation with watermelon pomace juice enhances arginine availability and ameliorates the metabolic syndrome in Zucker diabetic fatty rats, J Nutr. 137 (2007) 2680-2685.

[32] T. Lauer, M. Preik, T. Rassaf, B.E. Strauer, A. Deussen, M. Feelisch, M. Kelm, Plasma nitrite rather than nitrate reflects regional endothelial nitric oxide synthase activity but lacks intrinsic vasodilator action, Proc Natl Acad Sci U S A. 98 (2001) 12814-12819.

[33] S. McKinley-Barnard, T. Andre, M. Morita, D.S. Willoughby, Combined L-citrulline and glutathione supplementation increases the concentration of markers indicative of nitric oxide synthesis, J Int Soc Sports Nutr. 12:27 (2015).

[34] A.R. Davis, C.L. Webber III, W. Liu, P. Perkins-Veazie, A. Levi, S. King, Watermelon quality traits as affected by ploidy, HortScience. 48 (2013) 1113-1118.

[35] A.J. Edwards, B.T. Vinyard, E.R. Wiley, E.D. Brown, J.K. Collins, P. Perkins-Veazie, R.A. Baker, B.A. Clevidence, Consumption of watermelon juice increases plasma concentrations of lycopene and beta-carotene in humans. J Nutr. 133 (2003) 1043-1050. 
[36] P. Perkins-Veazie, J.K. Collins, A.R. Davis, W. Roberts, Carotenoid content of 50 watermelon cultivars, J Agric Food Chem. 54 (2006) 2593-2597.

[37] C.C. Trevithick-Sutton, C.S. Foote, M. Collins, J.R. Trevithick, The retinal carotenoids zeaxanthin and lutein scavenge superoxide and hydroxyl radicals: a chemiluminescence and ESR study, Mol Vis. 12 (2006) 1127-1135.

[38] A. Figueroa, M.A. Sanchez-Gonzalez, P.M. Perkins-Veazie, B.H. Arjmandi, Effects of watermelon supplementation on aortic blood pressure and wave reflection in individuals with prehypertension: a pilot study, Am J Hypertens. 24 (2011) 40-44.

[39] A. Figueroa, M.A. Sanchez-Gonzalez, A. Wong, B.H. Arjmandi, Watermelon extract supplementation reduces ankle blood pressure and carotid augmentation index in obese adults with prehypertension or hypertension, Am J Hypertens. 25 (2012) 640-643.

[40] A. Figueroa, A. Wong, S. Hooshmand, M.A. Sanchez-Gonzalez, Effects of watermelon supplementation on arterial stiffness and wave reflection amplitude in postmenopausal women, Menopause. 20 (2013) 573-577.

[41] A. Figueroa, A. Wong, R. Kalfon, Effects of watermelon supplementation on aortic hemodynamic responses to the cold pressor test in obese hypertensive adults, Am J Hypertens 27 (2014) 899-906.

[42] P.T. Cutrufello, S.J. Gadomski, G.S. Zavorsky, The effect of l-citrulline and watermelon juice supplementation on anaerobic and aerobic exercise performance, J Sports Sci. 33 (2015) 1459-1466.

[43] L.J. Wylie, J. Kelly, S.J. Bailey, J.R. Blackwell, P.F. Skiba, P.G. Winyard, A.E. Jeukendrup, A. Vanhatalo, A.M. Jones, Beetroot juice and exercise: pharmacodynamic and dose-response relationships, J Appl Physiol. 115 (2013) 325-336.

[44] N. Lamarra, B.J. Whipp, S.A. Ward, K. Wasserman, Effect of interbreath fluctuations on characterizing exercise gas exchange kinetics, J Appl Physiol. 62 (1987) 2003-2012. 
[45] B.N. Jones, J.P. Gilligan, o-Phthaldialdehyde precolumn derivatization and reversedphase high-performance liquid chromatography of polypeptide hydrolysates and physiological fluids, J Chromatogr. 266 (1983) 471-482.

[46] A.M. Rimando, P.M. Perkins-Veazie, Determination of citrulline in watermelon rind, J Chromatogr A. 1078 (2005) 196-200.

[47] M.P. Tarazona-Díaz, J. Viegas, M. Moldao-Martins, E. Aguayo, Bioactive compounds from flesh and by-product of fresh-cut watermelon cultivars, J Sci Food Agric. 91 (2011) 805-12.

[48] S.M. Jr. Morris, Enzymes of arginine metabolism, J Nutr. 134 (2004) 2743S-2747S.

[49] E. Curis, I. Nicolis, C. Moinard, S. Osowska, N. Zerrouk, S. Bénazeth, L. Cynober, Almost all about citrulline in mammals, Amino Acids. 29 (2005) 177-205.

[50] G. Wu, S.M. Jr. Morris, Arginine metabolism: nitric oxide and beyond, Biochem J. 336 (1998) 1-17.

[51] C.M. Jones, A. Lawrence, P. Wardman, M.J. Burkitt, Kinetics of superoxide scavenging by glutathione: an evaluation of its role in the removal of mitochondrial superoxide, Biochem Soc Trans. 31 (2003) 1337-1339.

[52] T.J. Guzik, N.E. West, R. Pillai, D.P. Taggart, K.M. Channon, Nitric oxide modulates superoxide release and peroxynitrite formation in human blood vessels, Hypertension. 39 (2002) 1088-1094.

[53] R.J. Maughan, D.C. Poole, The effects of a glycogen-loading regimen on the capacity to perform anaerobic exercise, Eur J Appl Physiol Occup Physiol. 46 (1981) 211-219.

[54] R.J. Maughan, P.L. Greenhaff, J.B. Leiper, D. Ball, C.P. Lambert, M Gleeson, Diet composition and the performance of high-intensity exercise, J Sports Sci. 15 (1997) 265-275. 
[55] A.E. Jeukendrup, Nutrition for endurance sports: marathon, triathlon, and road cycling, J Sports Sci. 29 (2011), Suppl 1:S91-9.

[56] E.P. de Oliveira, R.C. Burini, A. Jeukendrup, Gastrointestinal complaints during exercise: prevalence, etiology, and nutritional recommendations, Sports Med 44 Suppl 1 (2014) S79-85.

[57] T. Rebello, R.E. Hodges, J.L. Smith, Short-term effects of various sugars on antinatriuresis and blood pressure changes in normotensive young men, Am J Clin Nutr. 38 (1983) 84-94.

[58] J.B. Young, L. Landsberg, Stimulation of the sympathetic nervous system during sucrose feeding, Nature. 269 (1977) 615-617.

[59] B. Xi, Y. Huang, K.H. Reilly, S. Li, R. Zheng, M.T. Barrio-Lopez, M.A. MartinezGonzalez, D. Zhou, Sugar-sweetened beverages and risk of hypertension and CVD: a doseresponse meta-analysis, Br J Nutr. 113 (2015) 709-17. 


\section{Figure Legends}

Figure 1: Schematic of the experimental protocol (panel A) and the time to exhaustion (panel B) and all-out effort (panel C) tests that were completed in the control condition and during 16 day supplementation periods with watermelon juice concentrate and apple juice concentrate as a placebo. Tlim = time to exhaustion. Note that the watermelon juice and apple juice supplements were administered in a counterbalanced order in a crossover experimental design.

Figure 2: Plasma [L-citrulline] (upper panel), [L-arginine] (middle panel) and [nitrite] (lower panel) in the control (CON) condition and during a 16 day supplementation period with watermelon juice concentrate (WMJ) and apple juice concentrate as a placebo (PLA). The open bars represent the group mean \pm SD responses in the CON, WMJ and PLA conditions. The solid black lines represent the individual responses to the supplements. * indicates significantly different from CON and PLA $(P<0.05)$. \# indicates significantly different from CON $(P<0.05)$.

Figure 3: Group mean near-infrared spectroscopy-derived tissue oxygenation index during a moderate-intensity step cycle test (upper panel) and a severe-intensity step cycle test (lower panel) in the control (CON) condition and during a 16 day supplementation period with watermelon juice concentrate (WMJ) and apple juice concentrate as a placebo (PLA). Note the improved tissue oxygenation index with WMJ during moderate-intensity cycling exercise.

Figure 4: Group mean power profiles during a $30 \mathrm{~s}$ all-out effort commenced immediately after 6 min of severe-intensity cycle exercise in the control (CON) condition and during a 16 day supplementation period with watermelon juice concentrate (WMJ) and apple juice concentrate as a placebo (PLA). The dashed vertical line represents the onset of the 30-s allout effort. * indicates a significantly higher mean power output over the first 10 -s of the allout effort in the WMJ condition compared to the CON condition. 
Table 1. Resting blood pressure and heart rate measures during the control (CON), watermelon juice (WMJ) and placebo (PLA) conditions.

\begin{tabular}{|c|c|c|c|c|c|c|c|}
\hline & CON & WMJ & PLA & \multicolumn{2}{|c|}{ CON-WMJ } & \multicolumn{2}{|c|}{ PLA-WMJ } \\
\hline & & & & $\begin{array}{l}\text { Mean } \\
\text { Difference } \\
(95 \% \text { CI })\end{array}$ & $\begin{array}{l}\text { Effect } \\
\text { Size }\end{array}$ & $\begin{array}{l}\text { Mean } \\
\text { Difference } \\
(95 \% \text { CI) }\end{array}$ & $\begin{array}{l}\text { Effect } \\
\text { Size }\end{array}$ \\
\hline Heart rate (bpm) & $66 \pm 4$ & $76 \pm 6^{*}$ & $77 \pm 8 *$ & $\begin{array}{c}-9.88(- \\
16.12,- \\
3.63)\end{array}$ & 1.32 & $\begin{array}{c}0.50(- \\
7.68,8.68)\end{array}$ & 0.05 \\
\hline Systolic blood pressure (mmHg) & $124 \pm 8$ & $130 \pm 11^{*}$ & $131 \pm 9 *$ & $\begin{array}{c}-6.13(- \\
11.38,- \\
0.87)\end{array}$ & 0.98 & $\begin{array}{c}1.13(- \\
2.57,4.82)\end{array}$ & 0.26 \\
\hline Diastolic blood pressure (mmHg) & $68 \pm 4$ & $69 \pm 9 *$ & $68 \pm 7^{*}$ & $\begin{array}{c}-1.63(- \\
6.00,2.75)\end{array}$ & 0.31 & $\begin{array}{c}-1.00(- \\
8.21,6.21)\end{array}$ & 0.12 \\
\hline Mean arterial pressure (mmHg) & $89 \pm 5$ & $92 \pm 7^{*}$ & $92 \pm 7^{*}$ & $\begin{array}{c}-2.75(- \\
5.15,- \\
0.35)\end{array}$ & 0.96 & $\begin{array}{c}0.13(- \\
2.95,3.20)\end{array}$ & 0.04 \\
\hline
\end{tabular}

Values are presented as the mean \pm SD. * = significantly different from CON $(P<0.05) .95 \%$ $\mathrm{CI}=95 \%$ confidence interval. 
Table 2. Pulmonary oxygen uptake $\left(\dot{V}_{2}\right)$ during moderate- and severe-intensity cycle exercise in the control (CON), watermelon juice (WMJ) and placebo (PLA) conditions.

\begin{tabular}{|c|c|c|c|c|c|c|c|}
\hline & \multirow[t]{2}{*}{$\mathrm{CON}$} & \multirow[t]{2}{*}{ WMJ } & \multirow[t]{2}{*}{ PLA } & \multicolumn{2}{|c|}{ CON-WMJ } & \multicolumn{2}{|c|}{ PLA-WMJ } \\
\hline & & & & $\begin{array}{l}\text { Mean } \\
\text { Difference } \\
(95 \% \text { CI })\end{array}$ & $\begin{array}{l}\text { Effect } \\
\text { Size }\end{array}$ & $\begin{array}{l}\text { Mean } \\
\text { Difference } \\
(95 \% \text { CI) }\end{array}$ & $\begin{array}{l}\text { Effect } \\
\text { Size }\end{array}$ \\
\hline \multicolumn{8}{|l|}{ Pulmonary $\dot{V} \mathrm{o}_{2}$} \\
\hline \multicolumn{8}{|l|}{ Moderate-intensity cycling } \\
\hline Baseline $\left(\mathrm{L} \cdot \mathrm{min}^{-1}\right)$ & $1.10 \pm 0.18$ & $1.10 \pm 0.17$ & $1.08 \pm 0.15$ & $\begin{array}{c}-0.01(- \\
0.07,0.47)\end{array}$ & 0.14 & $\begin{array}{c}-0.02(- \\
0.10,0.64)\end{array}$ & 0.2 \\
\hline End-exercise $\left(\mathrm{L} \cdot \mathrm{min}^{-1}\right)$ & $1.84 \pm 0.40$ & $1.91 \pm 0.31$ & $1.91 \pm 0.29$ & $\begin{array}{c}-0.07(- \\
0.26,0.11)\end{array}$ & 0.32 & $\begin{array}{c}-0.02(- \\
0.08,0.05)\end{array}$ & 0.25 \\
\hline \multicolumn{8}{|l|}{ Severe-intensity cycling } \\
\hline Baseline $\left(\mathrm{L} \cdot \mathrm{min}^{-1}\right)$ & $1.13 \pm 0.18$ & $1.17 \pm 0.16$ & $1.17 \pm 0.12$ & $\begin{array}{c}-0.04(- \\
0.07,0.00)\end{array}$ & 0.75 & $\begin{array}{c}-0.00(- \\
0.08,0.08)\end{array}$ & 0.01 \\
\hline $360-\mathrm{s}\left(\mathrm{L} \cdot \mathrm{min}^{-1}\right)$ & $3.88 \pm 0.63$ & $3.84 \pm 0.64$ & $3.95 \pm 0.63$ & $\begin{array}{c}0.03(- \\
0.02,0.09)\end{array}$ & 0.50 & $\begin{array}{c}0.11(- \\
0.05,0.27)\end{array}$ & 0.58 \\
\hline Phase II time Constant (s) & $28 \pm 6$ & $26 \pm 3$ & $29 \pm 4$ & $\begin{array}{c}2.08(- \\
3.47,7.62)\end{array}$ & 0.31 & $\begin{array}{c}2.79(- \\
2.38,7.95)\end{array}$ & 0.45 \\
\hline $\begin{array}{l}\text { Fundamental amplitude } \\
\left(\mathrm{L} \cdot \mathrm{min}^{-1}\right)\end{array}$ & $2.16 \pm 0.52$ & $2.11 \pm 0.54$ & $2.23 \pm 0.52$ & $\begin{array}{c}0.05(- \\
0.08,0.19)\end{array}$ & 0.31 & $\begin{array}{c}0.11(- \\
0.02,0.25)\end{array}$ & 0.69 \\
\hline $\begin{array}{l}\text { Slow component amplitude } \\
\left(\mathrm{L} \cdot \mathrm{min}^{-1}\right)\end{array}$ & $0.61 \pm 0.14$ & $0.60 \pm 0.17$ & $0.60 \pm 0.16$ & $\begin{array}{c}0.01(- \\
0.09,0.10)\end{array}$ & 0.08 & $\begin{array}{c}0.00(- \\
0.08,0.08)\end{array}$ & 0.00 \\
\hline $\begin{array}{l}\text { Overall mean response time } \\
\text { (s) }\end{array}$ & $57 \pm 12$ & $58 \pm 9$ & $57 \pm 11$ & $\begin{array}{c}-0.10(- \\
4.66,4.46)\end{array}$ & 0.02 & $\begin{array}{c}-0.23(- \\
4.91,4.47)\end{array}$ & 0.04 \\
\hline End-sprint $\left(\mathrm{L} \cdot \mathrm{min}^{-1}\right)$ & $4.12 \pm 0.74$ & $4.08 \pm 0.57$ & $4.14 \pm 0.76$ & $\begin{array}{c}0.04(- \\
0.20,0.28)\end{array}$ & 0.14 & $\begin{array}{c}0.06(- \\
0.17,0.29)\end{array}$ & 0.22 \\
\hline Exhaustion $\left(\mathrm{L} \cdot \mathrm{min}^{-1}\right)$ & $3.99 \pm 0.48$ & $3.91 \pm 0.66$ & $4.04 \pm 0.59$ & $\begin{array}{c}0.08(- \\
0.12,0.29)\end{array}$ & 0.32 & $\begin{array}{c}0.13(- \\
0.12,0.39)\end{array}$ & 0.42 \\
\hline
\end{tabular}

Values are presented as the mean \pm SD. 95\% CI $=95 \%$ confidence interval. 
Table 3. Blood [glucose] and [lactate] during moderate- and severe-intensity cycle exercise in the control (CON), watermelon juice (WMJ) and placebo (PLA) conditions.

\begin{tabular}{|c|c|c|c|c|c|c|c|}
\hline & \multirow[t]{2}{*}{ CON } & \multirow[t]{2}{*}{ WMJ } & \multirow[t]{2}{*}{ PLA } & \multicolumn{2}{|c|}{ CON-WMJ } & \multicolumn{2}{|c|}{ PLA-WMJ } \\
\hline & & & & $\begin{array}{l}\text { Mean } \\
\text { Difference } \\
(95 \% \text { CI) }\end{array}$ & $\begin{array}{l}\text { Effect } \\
\text { Size }\end{array}$ & $\begin{array}{l}\text { Mean } \\
\text { Difference } \\
\text { (95\% CI) }\end{array}$ & $\begin{array}{l}\text { Effect } \\
\text { Size }\end{array}$ \\
\hline \multicolumn{8}{|c|}{$\begin{array}{l}\text { Blood glucose concentration } \\
(\mathrm{mM})\end{array}$} \\
\hline \multicolumn{8}{|c|}{ Moderate-intensity cycling } \\
\hline Baseline & $4.0 \pm 0.8$ & $4.1 \pm 0.7$ & $4.1 \pm 0.6$ & $\begin{array}{c}-0.13(- \\
1.08 \\
0.82)\end{array}$ & 0.11 & $\begin{array}{c}-0.02(- \\
0.74 \\
0.70)\end{array}$ & 0.02 \\
\hline End-exercise & $4.2 \pm 0.4$ & $3.8 \pm 0.9$ & $4.1 \pm 0.8$ & $\begin{array}{c}0.43(- \\
0.34 \\
1.20)\end{array}$ & 0.47 & $\begin{array}{c}0.25(- \\
0.52, \\
1.01) \\
\end{array}$ & 0.27 \\
\hline \multicolumn{8}{|c|}{ Severe-intensity cycling } \\
\hline Baseline & $4.0 \pm 0.8$ & $4.1 \pm 0.6$ & $4.3 \pm 0.5$ & $\begin{array}{c}-0.88(- \\
1.16 \\
0.99)\end{array}$ & 0.68 & $\begin{array}{c}0.23(- \\
0.50, \\
0.95)\end{array}$ & 0.26 \\
\hline $360-\mathrm{s}$ & $3.9 \pm 0.4$ & $4.2 \pm 0.5$ & $4.1 \pm 1.0$ & $\begin{array}{c}0.23(- \\
0.44,- \\
0.01)\end{array}$ & 0.89 & $\begin{array}{c}-0.38(- \\
0.71 \\
0.64)\end{array}$ & 0.47 \\
\hline Post 30-s sprint & $4.0 \pm 0.7$ & $4.0 \pm 0.5$ & $4.3 \pm 0.6$ & $\begin{array}{c}-0.01(- \\
0.63, \\
0.61)\end{array}$ & 0.01 & $\begin{array}{c}0.30(- \\
0.17 \\
0.77)\end{array}$ & 0.54 \\
\hline Post exhaustion & $3.4 \pm 0.9$ & $3.8 \pm 0.7$ & $4.1 \pm 1.0$ & $\begin{array}{c}-0.39(- \\
1.11 \\
0.33)\end{array}$ & 0.45 & $\begin{array}{c}0.31(- \\
0.40, \\
1.03)\end{array}$ & 0.36 \\
\hline \multicolumn{8}{|c|}{$\begin{array}{l}\text { Blood lactate concentration } \\
(\mathrm{mM})\end{array}$} \\
\hline \multicolumn{8}{|c|}{ Moderate-intensity cycling } \\
\hline Baseline & $0.9 \pm 0.3$ & $1.5 \pm 0.3^{*}$ & $1.4 \pm 0.3^{*}$ & $\begin{array}{c}-0.61(- \\
0.80,- \\
0.41)\end{array}$ & 2.65 & $\begin{array}{c}-0.11(- \\
0.27 \\
0.05)\end{array}$ & 0.58 \\
\hline End-exercise & $1.3 \pm 0.6$ & $1.6 \pm 0.5$ & $1.6 \pm 0.5^{*}$ & $\begin{array}{c}-0.26(- \\
0.60 \\
0.08)\end{array}$ & 0.63 & $\begin{array}{c}0.07(- \\
0.15, \\
0.28)\end{array}$ & 0.28 \\
\hline \multicolumn{8}{|c|}{ Severe-intensity cycling } \\
\hline Baseline & $0.9 \pm 0.3$ & $1.3 \pm 0.4^{*}$ & $1.3 \pm 0.3^{*}$ & $\begin{array}{c}-0.40(- \\
0.79,- \\
0.01)\end{array}$ & 0.87 & $\begin{array}{c}0.03(- \\
0.23 \text {, } \\
0.28)\end{array}$ & 0.10 \\
\hline $360-s$ & $6.9 \pm 1.7$ & $7.5 \pm 2.1$ & $7.4 \pm 2.0$ & $\begin{array}{c}-0.59(- \\
1.87,- \\
0.70)\end{array}$ & 0.38 & $\begin{array}{c}-0.08(- \\
1.44 \\
1.29)\end{array}$ & 0.05 \\
\hline Post 30-s sprint & $9.3 \pm 1.6$ & $9.6 \pm 1.5$ & $10.1 \pm 2.2$ & $-0.29(-$ & 0.79 & $0.51(-$ & 0.31 \\
\hline
\end{tabular}




\begin{tabular}{|l|c|c|c|c|c|c|c|}
\hline & & & & 1.24, & & 0.88, & \\
& & & & $0.66)$ & & $1.91)$ & \\
\hline Post exhaustion & $7.3 \pm 2.0$ & $8.4 \pm 2.5$ & $8.7 \pm 2.0$ & $-1.07(-$ & 0.46 & $0.34(-$ & 0.17 \\
& & & & 2.99, & & 1.30, & \\
& & & $0.86)$ & & $1.98)$ & \\
\hline
\end{tabular}

Values are presented as the mean \pm SD. $*=$ significantly different from CON $(P<0.05) .95 \%$ $\mathrm{CI}=95 \%$ confidence interval. 
Table 4. Exercise performance measures in the control (CON), watermelon juice (WMJ) and placebo (PLA) conditions.

\begin{tabular}{|c|c|c|c|c|c|c|c|}
\hline & CON & WMJ & PLA & \multicolumn{2}{|c|}{ CON-WMJ } & \multicolumn{2}{|c|}{ PLA-WMJ } \\
\hline & & & & $\begin{array}{l}\text { Mean } \\
\text { Difference } \\
(95 \% \text { CI) }\end{array}$ & $\begin{array}{l}\text { Effect } \\
\text { Size }\end{array}$ & $\begin{array}{l}\text { Mean } \\
\text { Difference } \\
(95 \% \text { CI })\end{array}$ & $\begin{array}{l}\text { Effect } \\
\text { Size }\end{array}$ \\
\hline Sprint test performance & & & & & & & \\
\hline Peak power output (W) & $509 \pm 167$ & $565 \pm 200$ & $547 \pm 196$ & $\begin{array}{c}-56.75(- \\
102.84,- \\
10.66)\end{array}$ & 1.03 & $\begin{array}{c}-18.38(- \\
75.05 \\
38.30)\end{array}$ & 0.27 \\
\hline Total work done over $10 \mathrm{~s}(\mathrm{~kJ})$ & $4.2 \pm 1.4$ & $4.7 \pm 1.7^{*}$ & $4.5 \pm 1.6$ & $\begin{array}{c}-0.54(- \\
0.93,- \\
0.16)\end{array}$ & 1.17 & $\begin{array}{c}-0.19(- \\
0.60,0.21)\end{array}$ & 0.39 \\
\hline Total work done over $30 \mathrm{~s}(\mathrm{~kJ})$ & $12.5 \pm 3.4$ & $13.2 \pm 4.5$ & $12.6 \pm 4.0$ & $\begin{array}{c}-0.65(- \\
1.79,0.49)\end{array}$ & 0.48 & $\begin{array}{c}-0.58(- \\
1.68,0.53)\end{array}$ & 0.44 \\
\hline Exercise Tolerance & & & & & & & \\
\hline Time-to-exhaustion (s) & $478 \pm 80$ & $550 \pm 143$ & $539 \pm 108$ & $\begin{array}{c}-72.25(- \\
\text { 169.49, } \\
24.99)\end{array}$ & 0.62 & $\begin{array}{c}-10.75(- \\
97.30 \\
75.80)\end{array}$ & 0.10 \\
\hline
\end{tabular}

Values are presented as the mean \pm SD. $*$ = significantly different from CON $(P<0.05) .95 \%$ $\mathrm{CI}=95 \%$ confidence interval. 

Figure 3

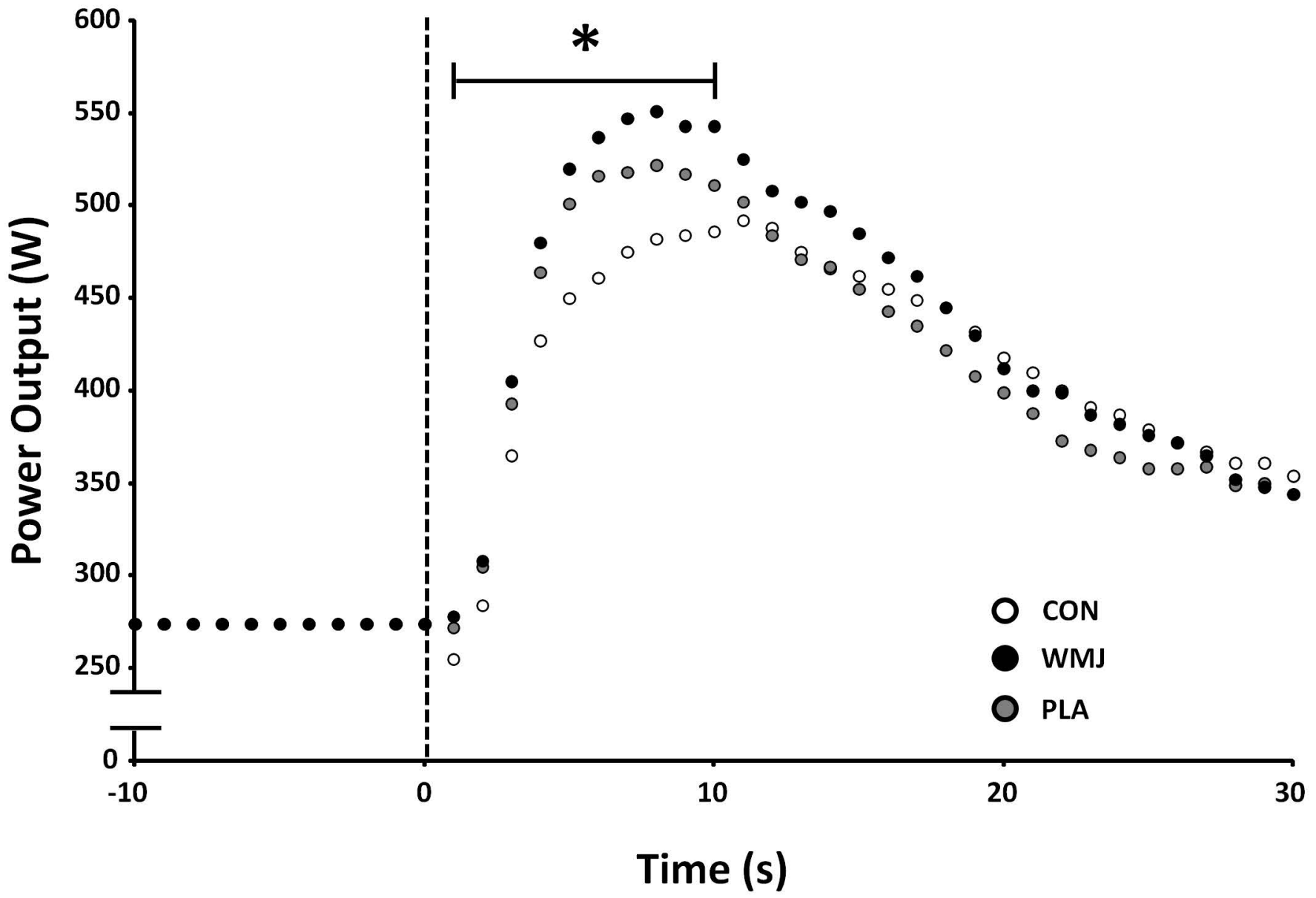

